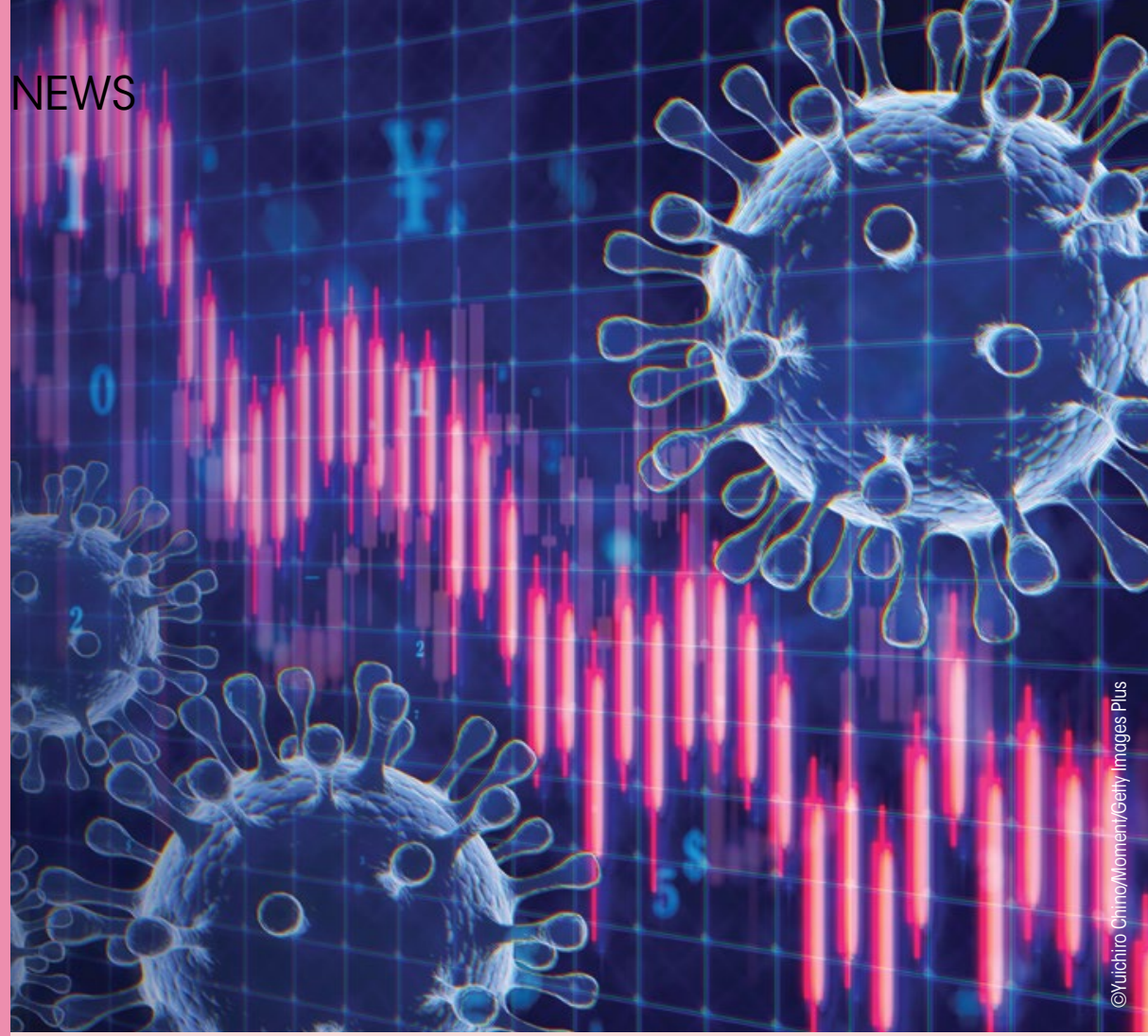

\title{
DENTAL DEAN WARNS OF POTENTIAL DENTAL NURSE REDUNDANCIES
}

Professor Phil Taylor, Dean of the Royal College of Surgeons of Edinburgh (RCSEd)'s Faculty of Dental Surgery, has voiced concerns around a potential wave of possible dental nurse jobs being put at risk as the profession continues to be plagued by financial uncertainty.

Professor Taylor warned that many dental practices may be forced to cut jobs due to current restrictions imposed on them as a result of the pandemic, particularly with them being able to see fewer patients.

Professor Taylor said: 'Many dental nurses have been furloughed during the pandemic and with the Job Retention Scheme due to finish [at the time of writing], we are in real danger of seeing these positions under threat.

'The tight restrictions on how many patients can be seen in a day has resulted in practices potentially needing less staff, and many have had to make tough decisions in order to survive financially.

'Dental nurses play a vital role in the dental profession and are an essential part of the team. It is of the utmost importance that we ensure they are supported through this period.

'For those who are returning to work, they need better support from the UK Government as well as the NHS as they adjust to new regulations, PPE and AGP procedures.
Jacqui Elsden, President of the British Association of Dental Nurses (BADN), said: 'Many dental nurses in NHS and mixed practices have not been paid their full, if any, salaries since March, despite the employing practices having received their NHS funding.

'Even when they are paid, dental nurses working in NHS practices are not regarded by the NHS as NHS employees - and are therefore denied access to NHS pensions and other benefits; nor are they paid according to NHS scales, but are often only paid minimum wage, despite the fact that they have to pay the GDC ARF, as well as indemnity and CPD costs.

'This is why BADN have launched a campaign for recognition of dental nurses, their contribution to oral healthcare and their vital role in the dental team. We encourage all dental nurses, and other members of the dental team, to lobby their MPs - a template letter is available on the BADN website.'

The RCSEd has previously warned that the current restrictions on dental practices could lead to the collapse of NHS dentistry in Scotland with practices forced to become private-only in order to survive the pandemic.

To download the BADN's template lobby letter, visit www.badn.org.uk or contact enquiries@badn.org.uk.
LETTER TO THE EDITOR

THE GDC SHOULD RAISE AWARENESS OF DENTAL TEAM ROLES

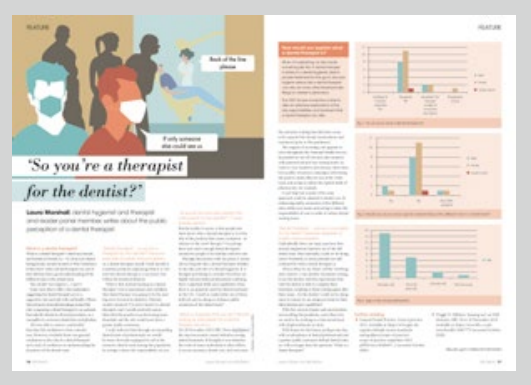

I am writing in response to Laura Marshall's article So you're a therapist for the dentist? in the October issue of $B D J$ Team (https://www.nature.com/articles/ s41407-020-0438-2).

I really enjoyed reading this. Well done to the author. We need a huge PR campaign: the GDC should lead so that the public know the roles in dentistry. The GDC don't seem to want to. As the regulator, they should raise awareness of the dental team, their roles and talents. Some great infograms could be really good as a public PR piece.

\section{Amanda Gallie}

Stefan Czerniawski, Executive Director, Strategy at the GDC, responds: We fully support all members of the dental team working to their full scope of practice and, of course, dental therapists are an important part of that. Better public understanding of roles within the team could help and, as Ms Marshall points out in her article in BDJ Team, the NHS has promoted the roles of the wider team in other areas of healthcare. Of course, dental professionals themselves also need to understand the roles within the team and, as our recent research on scope of practice revealed, ${ }^{1}$ awareness of others' roles in the team is low. The GDC is ready to do its part - and the findings of the research are feeding into our work to improve the scope of practice guidance - but this will not be a silver bullet and needs to be part of a wider collaborative approach.

\section{Reference}

1. General Dental Council. Scope of Practice review. 2 June 2020. Available at: https://www.gdc-uk.org/about-us/ what-we-do/research/research/detail/ fitness-to-practise/scope-of-practicereview (accessed November 2020). 